\title{
CONFLICTUL PERSISTENT, CARACTERISTICĂ A CONCEPȚIEI DE ABORDARE A RĂZBOIULUI HIBRID ÎN MEDIUL OPERAŢIONAL EST-EUROPEAN
}

\author{
THE PERSISTENT CONFLICT, A CHARACTERISTIC \\ OF THE CONCEPT OF APPROACHING THE HYBRID WAR \\ IN THE EASTERN EUROPEAN OPERATIONAL ENVIRONMENT
}

Lt.col.drd. Valentin PETRESCU*

\begin{abstract}
Mediul operațional contemporan est-european reprezintă un sistem complex de actori, arme și sisteme de arme, circumstanțe și condiții care se manifestă în spații bine definite și care pot influența în mod direct deciziile de întrebuințare a capabilităților militare. Acesta poate include atât forțele și sistemele de arme inamice, neutre sau aliate, participante la conflictul persistent, cât și cultura populației, mediul fizic, resursele locale, nivelul tehnologic, factorul de decizie politică și de execuție. Lecțiile învățate, din prima parte a acestui secol, ne-au convins că mediul operaţional est-european este destul de conflictual, în continuă transformare la nivel local şi regional, se încadrează într-un context dinamic, persistent și complex, care, combinat cu strategiile de șantaj energetic, favorizează apariția unor pericole și amenințări hibride la adresa stabilității și securității spațiului est-european. Prin acest articol, se dorește a se da un răspuns ferm și documentat unor întrebări legate de: concepția privind abordarea conflictului persistent de tip hibrid; tendința unor actori de a conferi un caracter persistent tensiunilor din zona de insecuritate est-europeană; preocuparea acestora de a menține conflictul persistent ca formă de manifestare modernă a relațiilor comunitare est-europene.
\end{abstract}

The Contemporary Eastern European operational environment is a complex system of actors, weapons and weapon systems, circumstances and conditions that manifest themselves in well-defined areas and that can directly influence decisions to use military capabilities. It may include both enemy and neutral or allied enemy forces and systems participating in the persistent conflict, as well as the culture of the population, the physical environment, local resources, the technological level, the political decision-maker and the executor. The lessons learned from the first part of this century convinced us that the Eastern European operational environment is quite conflictual; constantly changing at local and regional level, it falls into a dynamic, persistent and complex context, which, combined with energy blackmail strategies favor the emergence of hybrid dangers and threats to the stability and security of the Eastern European area. Through this article I want to give a firm and documented answer to questions related to: the conception of approaching the persistent hybrid conflict; the tendency of some actors to persist in tensions in the area of Eastern European insecurity and their concern to maintain the persistent conflict as a form of modern manifestation of Eastern European Community relations.

Cuvinte-cheie: mediul operațional; conflictul persistent; amenințări hibride; sistem operațional hibrid.

Keywords: operational environment; persistent conflict; hybrid threats; hybrid operating system.

În vederea realizării unei analize coerente, se va pleca de la ipoteza că actorii statali prezenți în mediul conflictual persistent se pot încadra într-o gamă variată de forțe, pornind de la structura unei forţe regulate, care aparţine unui stat, până la nivelul unor actori nonstatali, de tipul organizaţiilor nonguvernamentale sau guvernamentale care pot acţiona ferm, în scopul atingerii obiectivelor

*Universitatea Națională de Apărare „Carol I” e-mail: valipetrescu23@yahoo.com proprii. La acest scenariu, dacă adăugăm diferite organizaţii de crimă organizată şi/sau teroriste, avem tabloul complet, care constituie mediul operațional de desfăşurare a operațiilor militare. În acest sens, putem considera că mediul operațional se extinde dincolo de teatrul geografic de desfăşurare a acțiunilor conflictuale, fiind o arenă militară, în care aliniamentele și obiectivele sunt pierdute sau atinse prin folosirea forței letale sau prin folosirea timpului în care forţa de luptă poate reface și menține starea de siguranță și stabilitate a obiectivelor cucerite. Astfel, toţi actorii implicați, 
inamici sau aliaţi, nonstatali sau statali, indiferent de posibilitățile de luptă și de capabilităţile militare avute la dispoziție, vor folosi toate instrumentele de care dispun (militare, economice, politice și informaționale), în scopul atingerii obiectivelor propuse, pe timpul planificării operației.

În teoria științei militare a SUA, sunt definite elementele principale care pot influența planificarea și desfășurarea operațiilor militare specifice conflictului persistent, cum ar fi: globalizarea, schimbările demografice, nivelul tehnologic, cerinţele impuse de resurse, urbanizarea, dezastrele naturale și schimbările climatice, proliferarea armelor de distrugere în masă, statele eșuate sau prost guvernate etc. Astfel, „conflictul persistent este confruntarea prelungită dintre actori statali, nonstatali și individuali care sunt dispuşi să folosească violența pentru a atinge scopuri politice și ideologice" . Caracteristica principală a acțiunilor militare desfășurate în mediile operaționale hibride este aceea că misiunile de luptă îndeplinite cu mijloace neconvenționale pot fi mai numeroase și mai persistente, în comparație cu cele îndeplinite cu mijloace convenționale. Deseori, acest aspect derivă din configurația asimetrică a conflictelor persistente desfășurate în sistemul operațional hibrid, care poate include componente specifice tuturor mediile în care se pot executa operațiile militare: mediul informațional, mediul fizic, mediul geofizic, mediul moral etc.

\section{Concepția est-europeană privind abordarea conflictului persistent de tip hibrid}

Concepția de abordare a războiului hibrid a devenit importantă în mediul operațional esteuropean, ea a fost pusă în aplicare în conflictul rusoucrainean (2014) și susținută strategic de oficialii ruși. Astfel, în articolul intitulat „Valoarea științei în predicție", generalul Valeri Gherasimov (șef al Statului Major General al armatei ruse) afirma, la 1 septembrie 2015, că regulile războiului vor suporta schimbări importante în ceea ce privește caracterul persistent al acestuia. În acest sens, el susţine că „centrul de greutate al metodelor aplicate în conflict s-a modificat în direcţia utilizării pe scară largă a mijloacelor politice, economice, informaţionale, umanitare şi a altor măsuri nonmilitare, aplicate în coordonare cu protestul potenţial al populaţiei"’2. Mai mult, el susține că, în mediul conflictual modern, acţiunile asimetrice vor fi prezente și deosebit de active, făcând posibilă reducerea avantajelor unor adversari convenţionali, prezenţi în teatrul de operații. Gherasimov subliniază că o parte importantă a acțiunilor cu caracter asimetric va fi executată prin întrebuinţarea și a forţelor pentru operaţii speciale (FOS) sau printr-o cooperare strânsă cu forțe ale opoziţiei interne, în scopul menținerii unei situaţii conflictuale cu caracter persistent pe întreg teritoriul trupelor inamice. Aceste acțiuni vor fi mai eficiente, dacă vor fi executate cu mijloace informative şi tehnologice perfectionate.

Astfel, când vorbim despre conflictul modern, înţelegem că oficialii militari nu mai iau în calcul ameninţările separate, abordările în acest domeniu fiind fundamental diferite. Doctrina actuală a armatei ruse pune un accent important pe întrebuinţarea unor tactici, tehnici și proceduri noi de acţiune, combinate și cu acţiune simultană. În cadrul conflictului persistent, putem observa tendința convergenţei ameninţărilor de tip neregulat, în care actorii aflaţi în conflict recurg la o abordare cuprinzătoare, în scopul atingerii obiectivelor strategice. „Războiul nu se mai declară, ci odată început, se duce conform unui model nefamiliar", a adăugat șeful armatei ruse.

Este necesar să subliniem faptul că există diferenţe majore între strategia de abordare rusă, aplicată, în special, în Ucraina, şi strategia vestică. Aspectele care fac diferenţa dintre aceste tipuri de abordări este faptul că, în concepţia rusă, lipsesc din combinaţie ameninţările convenţionale. „Unul dintre obiectivele principale urmărite de ameninţările de tip hibrid este destabilizarea guvernării şi instituţiilor principale ale oponentului, prin aceasta creându-se haos şi vacuum de putere" "4, precizează Gherasimov. Căutând să obțină unele avantaje strategice și să atingă obiective sau aliniamente avantajoase prin tactici și proceduri neașteptate ori prin moduri violente de atac, teoreticienii militari ruși au renunţat la întrebuinţarea metodelor tradiţionale şi la predictibilitatea acţiunilor lor, motivând că aceasta e calea sigură de atingere a dezideratelor militare planificate.

Mai mult, ameninţarea hibridă este una invizibilă, greu de justificat şi, în consecință, nu poate fi demonstrată şi amendată de structurile legale internaţionale, deoarece sunt întrebuinţate sisteme de arme de ultimă generație, mijloace tehnologice performante, tactici neaşteptate şi 
proceduri inovative, specifice operaţiilor de tip asimetric. În esenţă, abordarea noului concept al conflictului persistent presupune o întrebuinţare concertată a unor elemente cheie, în măsură să activeze sentimentul de luptă al marelui popor rus, aceste elemente ${ }^{5}$ fiind:

- desfăşurarea acţiunilor sub acoperirea legii - elementul central al strategiei militare ruse este crearea unor aspecte perfect legale, în scopul evitării oricărei răspunderi în faţa organismelor legale internaţionale de securitate. În acest sens, un exemplu relevant este anexarea ilegală a Crimeii prin ocuparea și, ulterior, simularea unui referendum, fără supraveghere internaţională, prin care Moscova a reuşit să orchestreze anexarea Peninsulei Crimeea și stabilirea statutului acesteia, în afara voinţei populaţiei locale și a statului suveran Ucraina;

- demonstraţii de forţă militară - Armata Rusă a dislocat importante structuri de forţe militare, sisteme de arme şi mijloace logistice în proximitatea frontierei cu Ucraina, în scopul pregătirii operației ofensive, invadării teritoriului statului vecin și rezolvării prin forţă a unei situaţii de criză, creată la nivelul sistemului politic ucrainean;

- intrebuințarea „omuleților verzi” - balul mascat al lui Putin - pentru a nu atrage o răspundere politică în mediul internaţional, pe teritoriul Ucrainei, statul rus a întrebuinţat forţe speciale din batalionul Vostok (fără însemne militare), care au invadat teritoriul ucrainean ca forţe de securitate locale, scopul real al acestor operaţii fiind acela de a facilita intervenţia structurilor militare ruse în zonă, și nu de a proteja populaţia de naţionalitate rusă;

- folosirea avantajului creat de militiile locale şi de paravanul tensiunilor din zonă - Rusia şi-a protejat populaţia minoritară rusă, înainte de a începe operațiile militare, prin susţinerea şi gruparea acestora, asigurându-le un scut de protecție pe timpul desfãşurării intervenţiei în forţă;

- propagandă, minciuni și dezinformare sistematică ţintită - Rusia era conştientă de importanţa mass-mediei atât la nivel naţional, cât şi la nivel regional sau global, fapt pentru care a desfăşurat o vastă campanie de manipulare şi dezinformare a maselor, folosind mai multe componente ale războiului mediatic, care au transformat informaţia într-o armă redutabilă, astfel: acoperirea umanitară (motivarea acţiunilor ofensive cu argumente umanitare, în scopul atragerii unui sprijin consistent din partea mediului internaţional); dezinformare sistematică şi ţintită, în scopul activării sentimentului de luptă al poporului rus (mişcare folosită de ruși și împotriva invaziei naziste); negarea credibilă - argumente false și explicaţii bizare, oferite de oficialii ruşi în legătură cu scopurile invaziei (în sprijinul negării apartenenței omuleților verzi la Rusia, oficialii ruși au declarat că uniformele lor pot fi cumpărate din orice magazin second hand); Noua Rusie motivarea ajutorului dat rebelilor ruşi din Ucraina prin invocarea unor argumente istorice.

În concluzie, fizionomia conflictului persistent s-a aplicat perfect în situaţia invaziei din Ucraina (2014), fiind întrebuinţată simultan o combinaţie de acţiuni politice, economice, cibernetice, psihologice și de gherilă, care au provocat haos, au vulnerabilizat și au destabilizat autorităţile publice statale.

\section{Mediul fizic, mediul utilizării forței letale și al rezolvării conflictelor persistente}

Mediul fizic este mediul spaţiilor fizice, al entităţilor conflictuale, al acţiunilor şi al efectelor ce se manifestă în teatrul de operaţii. El include grupurile înarmate, forţele militare, populaţia civilă, infrastructura, resursele naturale, spaţiul geografic (aerian, terestru şi maritim), precum şi caracteristicile meteorologice (starea vremii, clima etc. $)^{6}$. Prin desfãşurarea operaţiilor în mediul fizic se urmărește dezorganizarea sau interzicerea activităţilor importante ale adversarului, prin utilizarea forţei letale sau neletale și prin executarea de manevre în întreaga zonă de operaţii. Majoritatea conflictelor persistente se rezolvă în mediul fizic, preponderent în zona spaţiului terestru, întrucât în acest mediu sunt plasate majoritatea resurselor participanților la conflict. De obicei, resursele au cea mai mare importanță în echilibrul balanței de putere, ele constituind centrul de greutate al operațiilor planificate în schema derulării conflictului persistent. De aici putem trage concluzia că efectul acțiunilor militare, desfăşurate în mediul fizic, este decisiv pentru distrugerea adversarului, sau pentru blocarea accesului acestuia la resursele necesare îndeplinirii obiectivelor planificate sau atingerii aliniamentelor/stării finale dorite.

Operaţiile militare desfăşurate în spațiul fizic al conflictului persistent prezintă două componente 
spaţiale (convenţională și cea neconvenţională), care definesc geometria mediului operaţional în care se îndeplinesc misiunile planificate de către participanţii la operaţie. Menţionăm faptul că, în condiţiile conflictelor trecute, nu foarte îndepărtate, geometria spaţiului operațional, la nivel operativ şi tactic, era destul de simplificată, era o geometrie a liniilor drepte, care defineau zone contigue. Mediul operaţional al conflictului persistent prezent este unul de tip hibrid, generat în cadrul desfăşurării conflictelor moderne, cu un aspect geometric complicat, în care zonele de conflict sunt concentrate în jurul unor zone cu bogate resurse energetice, sau în jurul unor obiective vizate de ameninţările de tip hibrid. Din perspectiva analizei dispunerii acestor obiective, folosind principiile conflictelor persistente convenţionale, putem înțelege că e vorba de o dislocare haotică, în realitate, obiectivele urmărite au o configuraţie de tip reţea, iar neutralizarea unui obiectiv poate afecta întreaga structură a rețelei de obiective.

Strategia amenințărilor persistente ia în calcul inclusiv spaţiul geografic al actorilor din zona care generează forţa militară, chiar dacă proiecţia forței şi desfăşurarea operațiilor se execută într-un teatru operațional aflat la o distanţă mare faţă de acesta. Totuşi, conceptul de teatru de război, definit ca „spaţiul terestru, aerian şi maritim care este sau poate fi implicat în mod direct în desfăşurarea operaţiilor majore sau campaniilor care impun lupta armată" a devenit destul de complex, având în vedere dimensiunea spaţială a mediului operaţional de tip hibrid, obiectivele strategice urmărite și gradul sporit de tehnologizare a sistemelor informații și comunicare.

În concluzie, rămânem la convingerea că în orice conflict, fie el persistent sau nu, operaţia decisivă necesită prezenţa şi acţiunea instrumentelor de forţă, iar menţinerea în atenţie a elementelor specifice geometriei mediului operaţional este necesară.

\section{Mediul informaţional, spaţiul de manifestare} a formelor de confruntare persistentă

Mediul informaţional este un mediu specializat în desfăşurarea proceselor şi acţiunilor militare persistente, care execută procurarea, prelucrarea şi utilizarea datelor și informaţiilor, fiind liantul dintre mediul moral şi mediul fizic. În esență, acest mediu constituie spaţiul ideal de manifestare a formelor de confruntare persistentă, care au, ca element central și integrator, informaţia cu privire la ansamblul măsurilor şi acţiunilor desfăşurate în scopul atingerii obiectivelor urmărite. În acest mediu, se pot executa acţiuni cu caracter nedistructiv sau distructiv.

Acţiunile persistente nedistructive se pot manifesta în scopul distorsionării percepţiilor colective sau individuale asupra situaţiei din câmpul tactic $^{8}$. Ţintele acestor acţiuni se regăsesc fie în spectrul sistemului militar (interceptare, spionaj, inducerea în eroare etc.), fie în spectrul comunităţii civile (spațiul de origine sau spaţiul de dislocare a forțelor), mai pregnant în zona personalului cu puteri de decizie, efortul acțiunilor nedistructive putând fi canalizat pe acţiunile psihologice, furnizare de informaţii false, propagandă, manipulare etc.

Acţiunile persistente distructive se pot desfăşura permanent, prin lovirea structurilor şi mijloacelor din compunerea fluxului informaţional (a elementelor din compunerea sistemului de comandă-control: centre de comunicaţii, puncte de comandă, senzori etc.) sau prin atacul asupra unor sisteme informatice (sisteme de comunicaţii, reţele de calculatoare, baze de date etc.).

Mediul informaţional modern, al structurilor militare, dispune de două componente: mediul cibernetic şi mediul electromagnetic.

Mediul electromagnetic este spaţiul operațional specific conflictelor persistente, în care se utilizează energia electromagnetică. De regulă, aceste acţiuni le preced pe cele executate în mediile moral şi fizic, iar realizarea la timp și cu succes a unora pot influenţa decisiv reuşita celorlalte. Războiul electronic, ca formă a conflictului persistent, reprezintă un cumul de acțiuni ofensive și defensive, care se desfășoară direct în mediul electromagnetic, mediu care poate fi exploatat, modelat și folosit pentru atac și/sau apărare 9 .

Mediul cibernetic este, de asemenea, un mediu propice conflictelor persistente moderne, cuprinde „totalitateasistemelordestinatecolectării,procesării şi distribuirii informaţiilor în sprijinul luării la timp a deciziei, al exercitării comenzii şi al controlului operaţiilor" ${ }^{\prime \prime}$, caracteristica de bază a acestui mediu fiind aceea că sistemele dispun de rețele de telecomunicații, procesoare integrate, sisteme de calcul și rețele informatice interdependente.

Din analiza zonei de insecuritate est-europene, rezultă că operaţiile desfășurate în mediul cibernetic 
au prezentat mai multe particularităţi ale conflictului persistent. Astfel, acestea au vizat: distrugerea, interzicerea, dezorganizarea și întârzierea colectării, prelucrării şi diseminării informaţiilor; folosirea unei palete variate de acțiuni specifice războiului informaţional (atacurile virtuale sau fizice asupra unor importante sisteme de informaţii ale adversarului); introducerea în sistem a unor informaţii false sau contradictorii; diminuarea puterii de luptă prin interzicerea sau denaturarea accesului adversarului la situaţia curentă ori prin afectarea capacităţii sale de conducere a acţiunilor; distrugerea sau afectarea arhitecturii sistemelor de calculatoare, a rețelelor informaționale, a bazelor de date, precum și a rețelei de Internet.

În concluzie, mediul informaţional est-european dispune, pentru decizie şi execuţie, de produse informaţionale performante, provenite din surse proprii, din surse conexe cu responsabilitate internă, externă, judiciară etc. Acesta înglobează, practic, toate acele sisteme informaţionale şi sursele deschise care operează în mediile de interes şi care îi facilitează asigurarea superiorităţii sau supremaţiei informaţionale, condiţie esenţială a conflictului persistent, necesară dominării câmpului de luptă. Prin efectele realizate în spaţiul forţelor ruso-ucrainene, se poate concluziona că operaţiile informaţionale, desfăşurate de structurile specializate rusești, au depăşit graniţele locale de desfăşurare a crizei din Ucraina, căpătând proporţii regionale şi internaţionale.

\section{Mediul moral, mediul de desfăşurare}

\section{a operațiilor psihologice persistente}

Mediulmoralcuprinde, atitudinile, convingerile şi determinările specifice indivizilor sau grupurilor de indivizi, manifestate prin voinţa acestora de a depăşi frica şi aversiunea şi de a realiza unitatea de efort, necesară îndeplinirii scopurilor/obiectivelor propuse prin planificarea conflictului persistent" ${ }^{\prime 1}$. Mediul moral include două componente de bază: componenta psihologică şi componenta cognitivă. Manifestările componentei psihologice se regăsesc în spectrul emoţional al individului, cum ar fi: sentimentul apartenenței etnice, patriotismul, credinţa în cauza pentru care luptă, zelul religios etc., iar nivelul de instruire, capacitatea de judecată și aspectele legate de îndoctrinare le vom regăsi în componenta cognitivă a individului uman.

În esență, operaţiile conflictului persistent care se desfăşoară în mediul moral țintesc influenţarea acelor comportamente şi atitudini ale personalului de conducere, ale comandanţilor, grupurilor, organizaţiilor sau indivizilor aparţinând aliaţilor, partenerilor, forţelor proprii, neutrilor sau adversarilor, care se manifestă vocal pentru îndeplinirea scopurilor şi obiectivelor forţelor proprii. Cele mai importante tipuri de operaţii specifice conflictului persistent care se desfăşoară în mediul moral sunt operaţiile mass-media şi operaţiile psihologice.

În operaţiile psihologice, desfășurate în mediul operaţional est-european, au fost vizate grupurile de oameni din spațiul de acțiune a forţelor armate, populaţia civilă, moralul și psihicul cetăţeanului, întrebuinţând informaţii, imagini şi un limbaj specific, care ar putea asalta mintea luptătorilor, ar leza atitudinea și voinţa acestora. Mai mult, aceste operații au avut efecte vizibile, au vizat procese volitive, afective şi cognitive, au modificat sentimente, au produs emoţii puternice, au avut continuitate şi au supus voinţa individuală sau colectivă la cele mai profunde niveluri ale emoției umane, în scopul slăbirii psihologice și morale a adversarului și înregistrării acestuia cu pierderi umane însemnate.

\section{Mediul geofizic, spațiul de manifestare a amenințărilor la adresa mediului înconjurător}

Războiului geofizic a fost experimentat și s-a dezvoltat în ultima parte a Războiului Rece, când, în mediul operaţional, au fost întrebuinţate tipuri noi de arme, denumite generic arme geofizice, cu efect asupra mediului înconjurător. În literatura de specialitate occidentală, a fost denumit război ecologic sau război meteorologic, în timp ce în literatura estică, s-a utilizat noțiunea de război geoclimatic. Specialiștii în domeniul conflictului persistent susțin că există forțe oculte care pot controla fenomenele generate de tornade sau uragane, folosindu-le pe post de arme devastatoare. De asemenea, aceștia apreciază că influențarea artificială a vremii, ca procedeu de luptă, prezintă pericolul potențial de a da naștere la distrugeri necontrolabile, cu urmări de neprevăzut. Faptul cel mai grav constă în probabilitatea mare ca asemenea distrugeri să aibă urmări mai grave pentru populație decât pentru forțele armate ${ }^{12}$.

Tehnica modificării mediului include un ansamblu de tehnici de schimbare a structurii 
sau compoziției Pământului (prin manipularea deliberată a proceselor naturale), inclusiv a spațiului cosmic, biosferei, hidrosferei, litosferei și atmosferei acestuia. Odată cu demararea schimbărilor climatice, a crescut și presiunea pentru realizarea de noi tehnologii, care ar putea declanșa blocarea căldurii soarelui sau ar putea aspira dioxidul de carbon din atmosferă. Multe dintre tehnologiile luate în calcul pot avea efecte imprevizibile, pot fi scăpate de sub control, ducând la pandemii cu acțiune universală, deoarece acestea au acțiune persistentă și nu respectă frontierele naționale. De multe ori, infrastructura civilă critică a fost vizată în conflictele regionale, iar actorii statali și nonstatali au o experiență îndelungată în manipularea mediului, în vederea avantajului tactic, implementarea tehnologiilor de geoinginerie fiind o sursă de noi amenințări la adresa securității mediului ambiant.

Daunele colaterale înregistrate la adresa mediului au fost considerate consecințe inevitabile ale conflictelor armate persistente. În același timp, au existat şi exemple de manipulare intenţionată a mediului ambiant de către majoritatea părților aflate în război, mediul devenind o armă de război. Sunt numeroase exemple, unele foarte vechi, în care forțele beligerante aflate în conflict, în mod deliberat, au adus prejudicii mediului de război. Astfel, tactica pământului ars este menită să distrugă o anumită zonă și să o lipsească de orice valoare pentru un adversar, pentru trupele proprii sau pentru civili. Această acțiune poate include distrugerea infrastructurilor civile critice, sursele de hrană și apă, adăposturile, resursele naturale etc. Armata sovietică a folosit această strategie în retragerea sa din Ucraina, în cel de-al Doilea Război Mondial, cu scopul de a încetini ofensiva trupelor germane.

Deteriorarea deliberată a mediului ambiant reprezintă o decizie, determinată de un ansamblu de condiţii naturale sau de activităţi umane periculoase, iresponsabile și dăunătoare sau de fenomene ale naturii grave, cu efecte directe și de lungă durată asupra securităţii și siguranței populației atât la nivel naţional, cât şi la nivel regional sau global. Dintre acestea, subliniem: catastrofele naturale, fenomenele geofizice sau meteo-climatice grave (inundaţii, furtuni puternice, secetă prelungită etc.), generate de încălzirea globală; modificările bruşte şi radicale ale condiţiilor de viaţă (alunecări de teren, cutremure etc.); catastrofele industriale sau ecologice, având drept consecinţe pierderi mari de vieţi omeneşti, perturbarea substanţială a vieţii economico-sociale şi poluarea gravă a mediului; probabilitatea în creştere a producerii unor pandemii, exemplul cel mai recent fiind pandemia declanşată de virusul A1H1 și de Covid-19. Aceste fenomene, în opinia mea, conferă factorului analizat un accentuat caracter potenţial conflictual, care, în condiţiile unor evoluţii nefavorabile, se pot transforma în război geofizic persistent.

Actorii care agreează strategia conflictului persistent folosesc adesea și infrastructurile critice pentru a obține un avantaj militar. Aceasta include utilizarea infrastructurii de mediu în scop strategic, cum ar fi unele rețele de apă (baraje, cursuri de apă, canale și lacuri), precum și instalațiile industriale deosebit de periculoase pentru mediu. O astfel de utilizare este banală, dar, pe măsură ce societățile au devenit dependente de infrastructura de mediu, pentru viaţa economică și socială, consecințele utilizării acestor amenajări împotriva părților aflate în război devin deosebit de grave (armarea infrastructurilor de apă oferă un astfel de exemplu). Astfel, barajele, stațiile de epurare, stațiile de pompare sau conductele pot fi obiectul unui atac deliberat pentru a pune în pericol populația civilă, pentru o perioadă foarte lungă. Formele armării apei sunt multiple, de la perturbarea sau devierea cursurilor de apă până la inundarea unor mari suprafețe de pământ, cu consecințe grave atât asupra forțelor combatante, cât și asupra populației civile.

\section{Concluzii}

Din analiza ameninţărilor de tip hibrid, rezultă că dimensiunea spaţială a mediului operaţional în care se desfăşoară conflictul de tip persistent se extinde mult peste limitele zonei de operaţii şi chiar ale teatrului de operaţii.

Operaţiile informaţionale sunt, pe zi ce trece, o categorie de acţiuni, al căror rol şi însemnătate nu mai pot fi neglijate, în contextul mutaţiilor care se produc în fenomenul conflictualităţii, caracteristic societăţii actuale, această tendinţă fiind imprimată de rolul atribuit informaţiei, care a devenit o adevărată armă, concretizată în concepte specifice conflictului persistent (precum, Războiul bazat pe reţea, Operaţiile bazate pe efecte etc.), rezultate din nevoia de creștere a eficacităţii operaţiilor, 
concomitent cu limitarea pierderilor de vieţi omeneşti şi a distrugerilor de bunuri materiale.

Faptul că, în timpul conflictelor armate, mediul a fost manipulat continuu, nu este și nu va fi o surpriză. În decursul istoriei, mediul a fost modificat în mai multe moduri și din mai multe motive, de la modificarea vremii până la modificarea fizică a peisajelor naturale. În afara conflictelor armate, modificările de mediu au fost, în general, implementate pentru a atenua riscurile de mediu sau pentru a îmbunătăţi accesul la resursele naturale.

Pericolul cauzat de anomaliile climatologice, de tipul cutremurelor, depinde de apropierea de surse potențiale, de magnitudinile acestora și de ratele de apariție exprimate în termeni probabilistici, pericolele putând include scuturarea solului, lichefierea, alunecările de teren ori producerea de tsunami, cele induse fiind, în general, mai mici ca magnitudine și cu durate scurte.

\section{NOTE:}

$1 * * *$ ADRP 3-0, Unified Land Operations, Department of the Army, Washington, 2012, cap. 1, p. 1-1.

2 Gl. Valeri Gherasimov, șeful Statului Major General din Federaţia Rusă, „Valoarea ştiinţei în predicţie” (1 septembrie 2015), Doctrina Gherasimov şi războiul nonliniar dus de Rusia pe teritoriul Ucrainei, http://romaniabreakingnews. ro/ doctrina-gherasimov-si-razboiul-non-liniar-dus-de-rusiapeteritoriul-ucrainei/; The value of science in prediction, https://inmoscowsshadows.wordpress.com/2014/07/06/thegerasimov-doctrine-and-russian-non-linear-war/, accesat la 05.03.2021.

\section{Ibidem.}

4 Ibidem.

5 Rebecca Blum, "The future of NATO in the face of hybrid conflict", Bernard El Ghoul, International Relations, Academic year 2014/2015, p. 5.

6 *** Doctrina Armatei României, București, 2018, p. 135.

7 *** JP 1-02, DOD Dictionary of Military Terms, US Department of Defense, Joint Education and Doctrine Division, 2010, https://www.jcs.mil/Portals/36/Documents/ Doctrine/pubs/dictionary.pdf, accesat la 05.03.2021.
8 Ion Bălăceanu, Florian Râpan, Marius Hanganu, Iulian Martin, Doina Mureșan, Valentin Dragomirescu, Interacțiunea strategiilor în conflictele armate moderne, Editura Universității Naţionale de Apărare „Carol I", Bucureşti, 2010, pp. 49-74.

$9 * * *$ Manualul de planificare a operaţiilor, Bucureşti, 2016, p. 195.

10 *** Doctrina Armatei României, Bucureşti, 2018, p. 134.

11 Ibidem, p. 135.

12 https://www.hotnews.ro/stiri-arhiva-1258889-roma nia-victima-razboiului-geofizic.htm, accesat la 05.03.2021.

\section{BIBLIOGRAFIE}

*** ADRP 3-0, Unified Land Operations, Department of the Army, Washington, 2012.

*** Doctrina Armatei României, Bucureşti, 2018.

*** JP 1-02, DOD Dictionary of Military Terms, US Department of Defense, Joint Education and Doctrine Division, 2010.

*** Manualul de planificare a operaţiilor, Bucureşti, 2016.

Bălăceanu Ion, Râpan Florian, Hanganu Marius, Martin Iulian, Mureșan Doina, Dragomirescu Valentin, Interacțiunea strategiilor în conflictele armate moderne, Editura Universităţii Naţionale de Apărare „Carol I”, București, 2010.

Blum Rebecca, "The future of NATO in the face of hybrid conflict", Bernard El Ghoul, International Relations, Academic year 2014/2015.

https://www.hotnews.ro

https://inmoscowsshadows.wordpress.com https://www.jcs.mil/Portals/36/Documents/ Doctrine/pubs/dictionary.pdf

ro/doctrina-gherasimov-si-razboiul-non-liniardus-de-rusiape-teritoriul-ucrainei/

https://inmoscowsshadows.wordpress. com/2014/07/06/the-gerasimov-doctrine-andrussian-non-linear-war/ 